\title{
Erratum to: A Latent Class Analysis of Heterosexual Young Men's Masculinities
}

\author{
Erin A. Casey ${ }^{1} \cdot$ N. Tatiana Masters ${ }^{2} \cdot$ Blair Beadnell $^{2} \cdot$ Elizabeth A. Wells $^{2} \cdot$ \\ Diane M. Morrison ${ }^{2} \cdot$ Marilyn J. Hoppe $^{2}$
}

Published online: 8 December 2015

(c) Springer Science+Business Media New York 2015

\section{Erratum to: Arch Sex Behav \\ DOI 10.1007/s10508-015-0616-z}

Readers should note that the following Acknowledgments should have been included in this article:

Acknowledgments This research was supported by a research project grant, R01 HD056952, to this research team (Morrison, PI) and from a research infrastructure grant, R24 HD042828, to the Center for Studies in Demography and Ecology at the University of Washington, both from the Eunice Kennedy Shriver National Institute of Child Health and Human Development.

The online version of the original article can be found under doi: $10.1007 /$ s10508-015-0616-z.

\section{Erin A. Casey}

ercasey@uw.edu

1 Social Work Program, University of Washington, 1900

Commerce, Box 358425, Tacoma, WA 98402, USA

2 School of Social Work, University of Washington, Seattle, WA 98105, USA 